\title{
Vulnerability Assessment of Reinforced Concrete Framed Structures Considering the Effect of Structural Characteristics
}

\author{
Ioana Olteanu ${ }^{1, *}$, Alex H. Barbat ${ }^{2}$ and Mihai Budescu ${ }^{1}$ \\ ${ }^{I}$ Faculty of Civil Engineering and Building Services, Technical University "Gheorghe Asachi” of Iasi, Romania \\ ${ }^{2}$ Technical University of Catalonia, Barcelona, Spain
}

\begin{abstract}
Considering the effects of earthquakes occurred during the last 15 years, this article focusses on finding solutions to minimize the human and economic losses. Several methodologies were developed in order to assess the vulnerability of the built environment with special reference to one of the most suitable structural systems in seismic areas for dwellings, offices or other functionalities, which is the reinforced concrete framed structure. Thus, the present article studies the influence on the vulnerability of reinforced concrete framed structures of geometric structural characteristics like the slab thickness, the building height and the plan configuration. Referring to the slab, it adds supplementary stiffness to the structure that can significantly influence upon its overall failure mechanism. 3D static nonlinear analyses are conducted by means of the SAP2000 computer program. The results are capacity curves which are used to develop the vulnerability curves. Three thicknesses are considered for the slab: $0.1 \mathrm{~cm}, 0.12 \mathrm{~cm}$ and $0.15 \mathrm{~m}$. Medium and high rise structures are considered, with 4, and 8 levels, respectively, in order to determine the influence of the building height on the vulnerability index. Three plan configurations of the buildings are compared: a square one, a rectangular one and an $\mathrm{L}$ shaped one. For all the analyzed cases, the corresponding vulnerability curves are compared. The obtained results reveal that more realistic results for the behavior of the structure can be obtained if special attention is given to the structural characteristics, especially during the conceptual design process.
\end{abstract}

Keywords: Building height, plan configuration, pushover analysis, reinforced concrete framed structures, slab thickness, vulnerability curves.

\section{INTRODUCTION}

Human and economic losses due to natural hazards that occurred in past decades increased the researchers concern to reevaluate the building stock in order to reduce these casualties. Risk evaluation and reduction are the first necessary steps in reducing the consequences of natural disasters. Referring to the seismic case, the seismic hazard and the vulnerability of structures cause risk. Both of these risk components have inherent uncertainties having their origin in the characteristics of the seismic action [1] and in the structural models [2-4]. These uncertainties have to be treated by performing stochastic simulations [5].

It was noticed that among the possible structural systems that can be adopted, the reinforced concrete (RC) structure is widely spread in the building stock all around the world, especially in seismic areas. This is due to the advantages this structural system presents, such as flexibility, easy execution and so on. Unfortunately, many of the existing RC structures were built without accounting the seismic actions which lead to poor detailing of the RC elements and, therefore, much attention has been paid in recent years to develop reliable methods of analysis, design and assessment this type of

*Address of the corresponding author at the Faculty of Civil Engineering and Building Services, Technical University "Gheorghe Asachi" of Iasi, Romania, D. Mangeron street no. 1, 700050; Tel: +40742459730;

E-mail: olteanuioa@yahoo.com structures [6]. Linear methods seem inappropriate in most cases; many current seismic codes and guidelines include provisions for nonlinear analysis [7-9], which seems to be the natural choice for the evaluation of the behaviour of existing structures subjected to moderate and strong design earthquakes [10].

Therefore, the seismic vulnerability assessment of $\mathrm{RC}$ buildings is extremely important in the mitigation of the earthquake effects, in order to reduce their consequences. Even though most of the seismic losses are likely to occur due to the damage of existing buildings, the attention of researchers, professionals or policy makers has largely focused so far on enhancing the seismic design prescriptions for new buildings [11, 12].

Seismic risk assessment of a structure requires several steps: hazard definition, assessment of the building capacity and development of vulnerability curves. Building vulnerability quantifies the damages that a structure can undergo when subjected to a seismic load. The response of a structure subjected to seismic load depends on various parameters, that sometimes are difficult to be estimated, like ground motion characteristics, deformation limit states of the structure, mechanical characteristics of the materials, state of the elements and of the entire structure, soil characteristics allowing to consider the soil-structure interaction, configuration in plan and height of the building, etc. [13, 14]. Most of these factors can be estimated but rarely their values are precise. 
In this article, we study the influence upon the seismic vulnerability of the reinforced concrete framed structures of geometric structural characteristics like slab thickness, building height and plan configuration. Thus, its main objective is to quantify the influence of these parameters upon seismic vulnerability and to propose solution for the vulnerability reduction for the case of $\mathrm{RC}$ structures.

\section{BACKROUND}

Multiple researches have been carried out in the past in order to evaluate and reduce seismic losses [15-18]. The reduction of the seismic vulnerability of RC structures was also the object of many articles, which start from its assessment by using different computational models and structural response analysis methods [19-21]. Griffith and Pinto (2000) studied the vulnerability of a "weak-column strong-beam" RC frame with 4 stories and 3 bays with infilled brick masonry. The maximum lateral deformation of about $2 \%$ of the lateral drift was expected. Nevertheless, the infill walls of the building start cracking at smaller lateral drifts, of $0.3 \%$, and they completely lost their load carrying capacity at a lateral drift between $1 \%$ and $2 \%$ [22]. Otani (2000) investigated the earthquake resistant design for RC buildings and showed the improvement of the performance of the building with the improvement of design methodology [23]. Guidelines for seismic evaluation and strengthening of buildings were proposed by Rai (2005) [24]. Goel (2008) evaluated the nonlinear static procedures specified in the FEMA-356, ASCE/SEI 41-06, ATC-40, and FEMA-440 documents regarding the seismic analysis and evaluation of RC buildings using strong-motion records [25]. It was shown that the nonlinear static procedures either overestimates or underestimates the peak roof displacement and that the improved FEMA-440 Capacity Spectrum Method provides better estimates roof displacement as compared to the ATC-40 methodology.

Ozer and Erberik (2008) observed that the number of story influences significantly the fragility curves that are used to evaluate the vulnerability of low-rise and mid-rise buildings in Turkey. They also state that a probabilistic approach would be more accurate to determine the vulnerability of the buildings and that the structural damage shifts from lower to higher levels when the structural subclass quality decreases, especially for high peak ground velocities [26].

Cosenza and Monti (2009) investigated several vulnerability factors for RC frame structures in the ReLUIS-DPC 2005-2008 Project. They examined the possibility of using non-destructive methods for the knowledge of behavior of existing structures, calibration of confidence factors, assessment of the nonlinear behavior of buildings with emphasis on irregular ones, assessment and strengthening of mixedtype buildings (masonry/RC), influence of infills on structural response, behavior and strengthening of stairs and behavior and strengthening of beam-column joints [27].

Sattar and Liel (2010) quantified the effect of the masonry infill upon the risk of seismic collapse of buildings. The masonry panels were modeled as two strut elements with nonlinear behaviour, subjected only to compression forces. The infilled frames exhibit an increase in the initial strength and stiffness, and also increased energy dissipation when it was compared with the bare frame, even for brittle failure modes of the wall. They concluded that the addition of walls leads to higher strength and energy dissipation capacity and to a better collapse performance of the fullyinfilled frames [28].

Lantada et al. (2010) described the Risk-UE vulnerability index method for assessing vulnerability and possible losses in urban areas [29] while Irrizari et al. (2011) made a detailed analysis on the seismic damage evaluation using the capacity spectrum method [30]. Both methods were applied to the entire building stock of the city of Barcelona, Spain, considering various seismic scenarios.

Monavari et al. (2012) used the nonlinear static analysis and different yielding and failure criteria to evaluate the seismic demand requirements for buildings. They studied $13 \mathrm{RC}$ buildings with $2-12,16$ and 20 levels and with 3 and 4 bays, designed for seismic actions corresponding to the Iranian Seismic Code 2005 and also to the ACI318-99 Building Code. They modeled the buildings by using the IDARC code [31].

Bakhshi and Ansari (2014) focused on the development of seismic fragility curves for tall buildings [32]. The vulnerability of the elements was specified using the slightly modified cumulative combined damage index of Park \& Ang (1985) and, thereby, the overall damage measure of the structure was calculated [33]. The evaluations of different damage indices showed that the uncertainty in the parameters of the seismic action has the most significant impact on the simulated seismic behavior of the structures, being more important than all other uncertainties considered in this analysis. Hence, it is necessary to ponder this source of randomness in the risk assessment of the structures. The fragility curves and relationships they developed are applicable to this specific type of tall buildings; additional investigations are needed to obtain general fragility relationships for other types of structures [32].

Esteva (2014) studied the vulnerability assessment and the performance-based design of irregular buildings characterized by non-uniform distributions of mass, lateral stiffness or strength, either in plan or along the building height, capable of generating significant concentrations of local ductility demands. Thus, local deformation demands greater than the corresponding deformation capacities may be reached for ground motion intensities significantly lower than those predicted in terms of conventional criteria. Strong-beam weakcolumn building structures and systems with asymmetric force displacement functions and tall buildings with slender shear walls coupled by shear links are included in this category [34].

\section{METHODOLOGY}

In order to reveal the influence on the vulnerability curve of the slab thickness, number of levels and plan configuration, several static nonlinear analyses (pushover analyses) were performed using computational models and computer programs like SAP2000 [35]. The result of a pushover analysis is the capacity curve which represents a relation between total base shear and the top displacement, and which is able to indicate premature failure or weakness of the structure. All the beams and columns which reach yield or have experienced crushing and even fracture are identified. This 
method is nowadays the most utilized for both design and seismic performance assessment purposes [36]. However it involves certain approximations which put up for a discussion the accuracy in estimating the global and local seismic demands of the structures, making mandatory the analysis for different height regime, with the consideration of the modeling particularities of each structural type [15]. Pushover analysis allows studying the elastic and inelastic response of structures subjected to seismic actions provided that adequate computational models are used and that an adequate lateral load pattern is applied upon the structure. This type of analyses is recommended for low to mid-rise buildings whose seismic response is predominantly based on the fundamental mode of vibration [14]. In the case of highrise buildings, other procedures should be considered in order to incorporate in the pushover analysis the effect of higher modes whose influence can lead to a significantly different structural response [37-40].

The capacity curve of the structure is converted into capacity spectrum by means of relations provided by ATC-40 [9]. The capacity spectrum is expressed and graphically represented in spectral acceleration and spectral displacement coordinates ( $\mathrm{S} a-\mathrm{S} d)$; it is mostly used in its simplified bilinear form which is completely defined by the yielding point $(D y, A y)$ and by the ultimate capacity point $(D u, A u)$ [16]. Four damage states are considered with the aim of analyzing the expected damage, namely, slight, moderate, severe and extensive-to-collapse. The damage states thresholds are used to determine the fragility curves for each of these damage states. In this article, we considered the definition of $d s$ made in the RISK-UE project which is based on the $(D y$, $A y)$ and $(D u, A u)$ points of the bilinear capacity spectrum [40-43]:

$$
\begin{aligned}
& d s_{1}=0.7 * D y \\
& d s_{2}=D y \\
& d s_{3}=d s_{2}+0.25 *\left(D s_{4}-D s_{2}\right) \\
& d s_{4}=D u
\end{aligned}
$$

The fragility curves express the probability that the expected global damage $d$ of a structure exceeds a given damage state $d s i$, in function of a parameter which quantifies the intensity of the seismic action; it usually follows a standard lognormal cumulative probability distribution. The fragility curve is completely defined for each damage state by the following equation [4]:

$$
P[d s i \mid S d]=\Phi\left[\frac{1}{\beta_{d s i}} \ln \left(\frac{S d}{\overline{S d}_{d s i}}\right)\right]
$$

where $S d$ is seismic hazard parameter which, in this case, is the spectral displacement, $S d_{d s i}$ is the threshold spectral displacement at which the probability of the damage state $d s$ is $50 \%, \beta d s i$ is the standard deviation of the natural logarithm of this spectral displacement, and $\Phi$ is the standard normal cumulative distribution function $[3,4,16]$. Usually, the fragility curve is represented graphically by plotting $P[d \geq d s i]$ on the $y$ axis and the spectral displacement $S d$ on the $x$ axis.

The overall normalized mean damage index $D I$ of a structure is expressed as

$$
D I=\frac{1}{n} \sum_{i=0}^{n} i P\left(d s_{i}\right)
$$

where $n$ is the number of non-null damage states ( $n=4$ in this case) and $P(d s i)$ is the probability of the damage state $i$ which can be easily calculated from the fragility curves, as it can be seen in Fig. (1) [16]. The overall damage index takes into account that the higher damage states $d s i$ have more influence on the global damage state $D I$ of the structure than the lower ones. The vulnerability curves express $D I$ as a function of the spectral displacement $S d$. The values of the coefficients of the probabilities of the damage states of Eq. (3), which are $0.25,0.5,0.75$ and 1.0 , can be calibrated from available observed damage values, improving thus the value of the damage index $D I$.

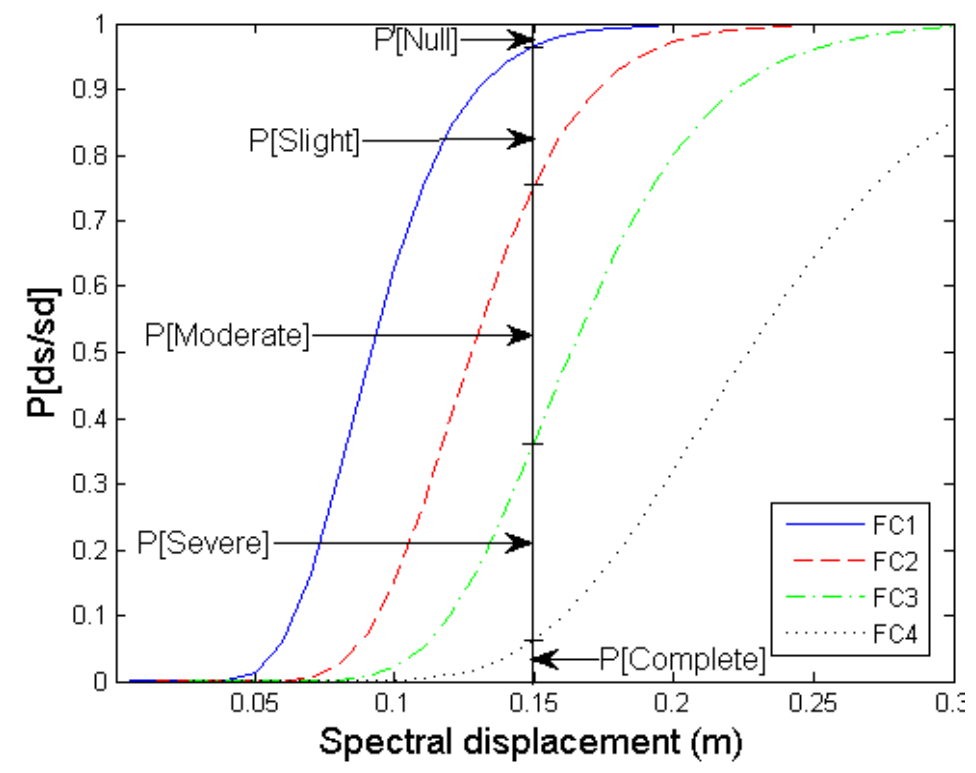

Fig. (1). Fragility curves and the occurrence probability of each damage state for a given spectral displacement. 
Table 1. List of the considered cases.

\begin{tabular}{|c|c|c|c|}
\hline Studied Structure Name & Slab Thickness (m) & Plan Configuration & Number of Levels \\
\hline 1 & 0.10 & square & 4 \\
\hline 2 & 0.12 & square & 4 \\
\hline 3 & 0.15 & square & 4 \\
\hline 4 & 0.10 & square & 8 \\
\hline 5 & 0.12 & square & 8 \\
\hline 6 & 0.15 & square & 8 \\
\hline 12 & 0.10 & rectangle & 4 \\
\hline 22 & 0.12 & rectangle & 4 \\
\hline 32 & 0.15 & rectangle & 4 \\
\hline 42 & 0.10 & rectangle & 8 \\
\hline 52 & 0.12 & rectangle & 8 \\
\hline 62 & 0.15 & rectangle & 8 \\
\hline 13 & 0.10 & L shape & 4 \\
\hline 23 & 0.12 & L shape & 4 \\
\hline 33 & 0.15 & L shape & 4 \\
\hline 43 & 0.10 & L shape & 8 \\
\hline 53 & 0.12 & L shape & 8 \\
\hline 63 & 0.15 & L shape & 8 \\
\hline
\end{tabular}

\section{CASE STUDY}

\subsection{Description of the Studied Structures}

In order to investigate the influence of several structural characteristics on the vulnerability index, we considered various situations. Previous research of the authors show the importance of the supplementary stiffness the slab brings to the overall behavior of the structure [44]. This is the reason why more detailed comparisons were made herein. The slab thickness dimensions were chosen considering the most frequent dimension used for RC frame structures. In order to emphasize the influence of the plan configuration of the structure, three shapes were considered: a square one, a rectangular one and an $\mathrm{L}$ shape. In previous research, the authors observed that low RC frame structure tend to be very rigid [45] and, for this reason, in this paper the comparisons focus on mid-rise and high-rise structures. Table 1 shows a summary of all the analyzed structures. Considering this table, the cases are further referred to in the comparisons made in the article as in "studied structure name" column.

Each structure has a story height of $3 \mathrm{~m}$ and a spam of 6 $\mathrm{m}$ in both directions. The cross sections of the columns are of $0.5 \mathrm{mx} 0.5 \mathrm{~m}$ and the cross sections of the beams are of $0.3 \mathrm{mx} 0.5 \mathrm{~m}$, considered constant for the whole structures. The studied structures are situated in the city of Iasi, Romania, and the specific materials for that area are used: C20/25 for the concrete and PC52 and OL37 for the longitudinal and transversal reinforcement, respectively. The structures were designed with medium ductility, importance class III and considering the design spectrum from Fig. (2). For the rectangular plan shape configuration, 4 spans were considered in both directions; meanwhile, for the rectangular shape plan configuration, the considered model had 8 openings on $\mathrm{x}$ direction and 4 on $y$ direction, meanwhile for the $\mathrm{L}$ shape plan configuration 8 spans were considered on both directions.

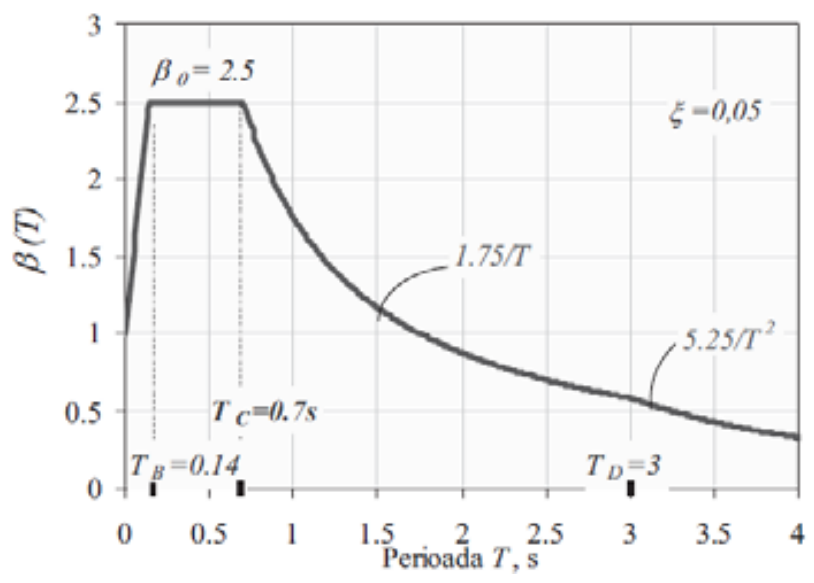

Fig. (2). Design spectrum according to P100-2013 [46]. 


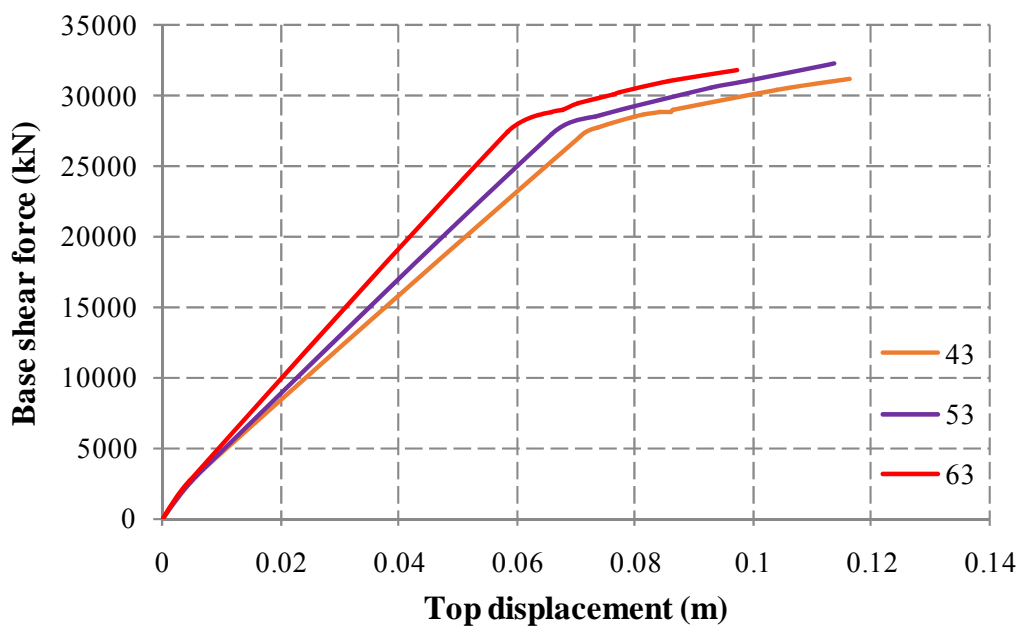

Fig. (3). Capacity curves for 8 levels, L shape plan for slab thicknesses of $0.10,0.12$ and $0.15 \mathrm{~m}$.

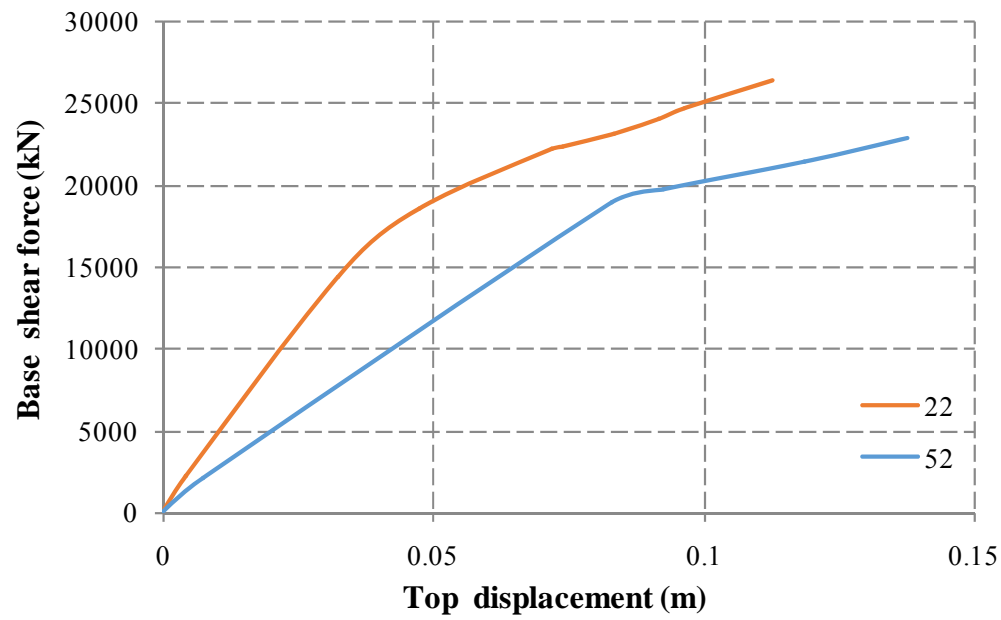

Fig. (4). Capacity curves for rectangular plan configuration with $0.12 \mathrm{~m}$ slab thickness and 4, respectively 8 story.

\subsection{Pushover Analysis Results}

The nonlinear static incremental analysis (pushover) was performed with the SAP2000 computer program and the obtained results consisted in capacity curves but also in plastic hinges and failure mechanisms. In order to study the influence of the thickness of the slab on the overall behavior of the structure, the parameters referring to plan configuration and number of levels were kept constant and only the slab thickness was varied during the performed analyses. Considering the notations of Table $\mathbf{1}$, the capacity curves were compared in the following cases: 1, 2 and 3;12, 22 and 32; 13,23 and $33 ; 4,5$ and $6 ; 42,52$ and $62 ; 43,53$ and 63. It was noticed that no matter what situation was investigated square plan configuration with 4 levels, rectangular plan configuration with 4 levels, L shape plan configuration with 4 levels or all these cases but with 8 levels- the results are similar. The general tendency is that, when the slab thickness increasing is incresed, the stiffness of the structure also increases. This is reflected by a higher base shear force and a lower maximum displacement.
Fig. (3) shows the comparison made for the capacity curves considering $\mathrm{L}$ shape plan configuration, 8 story structure with slab thicknesses of $0.1,0.12$ and $0.15 \mathrm{~m}$. For the studied case 43 (slab thickness of $0.1 \mathrm{~m}$, rectangular plan configuration, 8 levels structure) the top displacement is maximum, $0.116 \mathrm{~m}$, and the maximum base shear is minimum, $31247 \mathrm{kN}$. Meanwhile, if a thickness of $0.15 \mathrm{~m}$ would be considered, the rest of the parameters remaining constant (studied case name 63), the maximum top displacement would reach only $0.0197 \mathrm{~m}$ and the maximum base shear would be $31902 \mathrm{kN}$. In this particular case, for an increase of $0.05 \mathrm{~m}$ in the slab thickness, the top displacement decreases with $16 \%$ and the base shear force increases with $2.5 \%$.

In the case when the slab thickness and the plan configuration parameters are kept constant and the influence of the number of levels is investigated, it was noticed that the general tendency is that the bearing capacity decreases with the number of story. Fig. (4) compares structures with rectangular plan configuration, with $0.12 \mathrm{~m}$ slab thickness for midrise structures (4 story, studied case 22 ) and high-rise structures ( 8 story studied case 22 ). An increase with $20 \%$ of the 


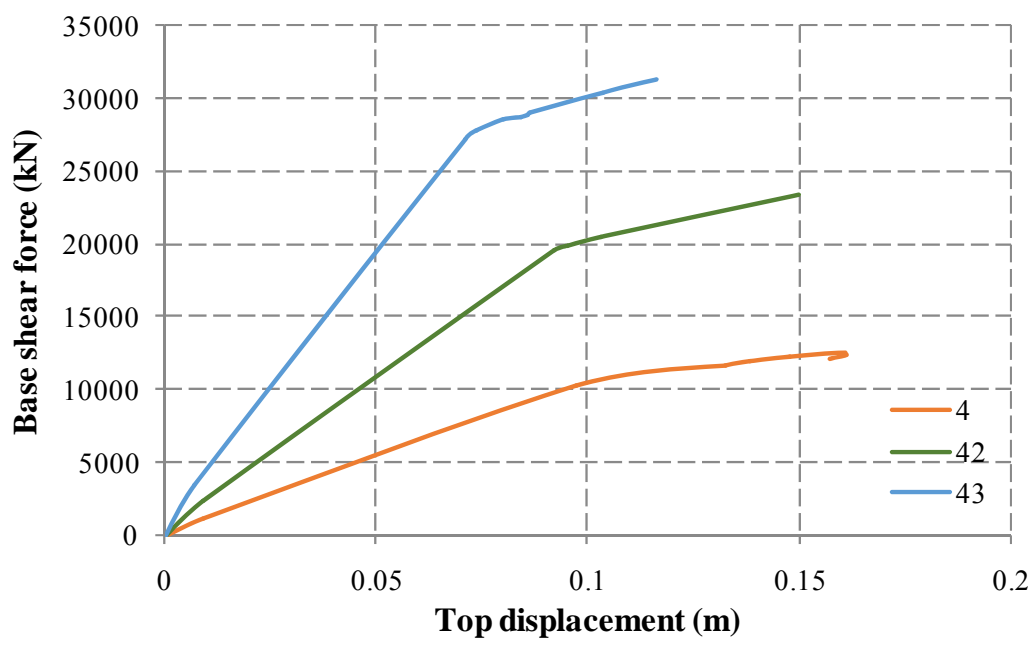

Fig. (5). Capacity curves for 8 levels building with $0.1 \mathrm{~m}$ slab thickness considering different plan configurations: square, rectangular and L shape.

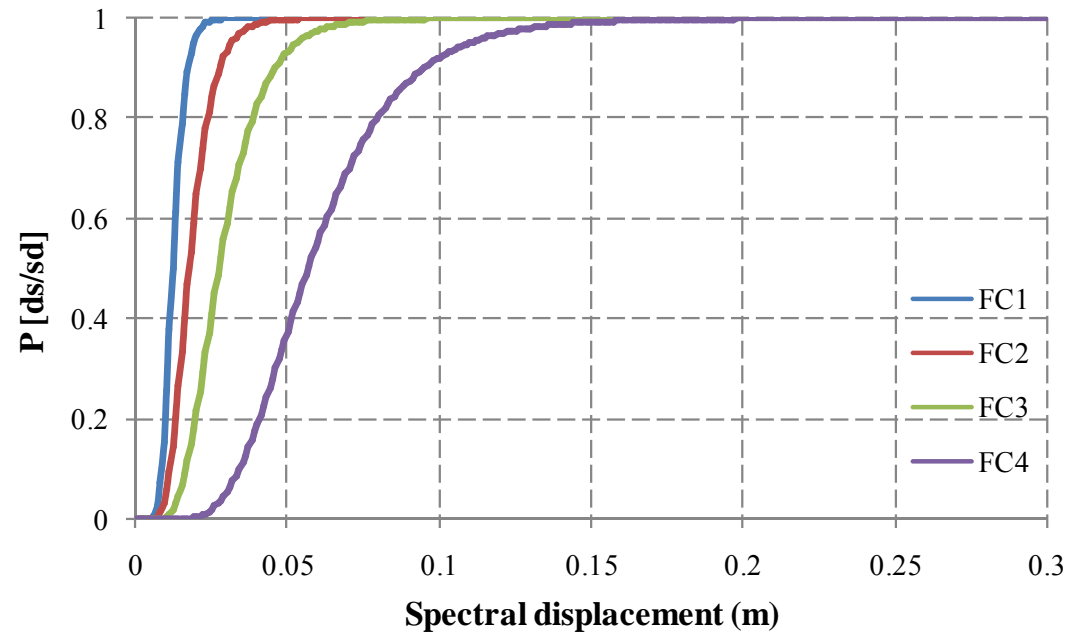

Fig. (6). Fragility curves for a square plan configuration structure, $0.12 \mathrm{~m}$ slab thickness with 4 story.

top displacement and a decrease of $14 \%$ were observed when the number of levels increased from 4 to 8 .

The capacity curves of Fig. (5) which correspond to a constant slab thickness of $0.1 \mathrm{~m}$ and 8 levels are compared for different plan configurations. It is noticed that the $\mathrm{L}$ shape plan configuration (studied case denoted by 43 in Table 1) has the highest capacity curve and the square one (studied case denoted by 4 ) has the lowest values for the capacity curve. This result is due to the fact that adding columns leads to stiffness increase which, consequently, leads to a better behavior in case of horizontal action.

It is important to observe that the performed pushover analyses do not capture the effect of the global structural torsion. Even so, a more detailed analysis is required, especially because it is well known that composed plan configuration geometry are not adequate in seismic areas due to additional stresses that appear at the intersection. Seismic regulations recommend dividing these complex structures into simpler ones, with seismic joints. In these 3 cases, the failure mechanism consists in the failure of the columns of the ground floor level, what means that stronger columns should be adopted at this level.

\subsection{Vulnerability Assessment Results}

The seismic vulnerability of the studied buildings is evaluated by calculating first of all the fragility curves for each structure using the methodology described above. Fig. (6) shows the fragility curves for a square plan configuration structure with 4 story and $0.12 \mathrm{~m}$ slab thickness. Considering the difficulty in comparing fragility curves for the different analyzed cases, vulnerability curves were calculated by using Equation (3) and plotted then in Fig. (7) in function of the spectral displacement. They allow assessing the damage probability for each value of the spectral displacement. The advantage of these representations is the easier way to visualize the vulnerability by representing the variation of the damage index in function of the spectral displacement, what allows the comparison among several cases. Vulnerability curves are used not only by researchers, but also by design engineer in order to conclude on the overall behavior of a structure in case of a known earthquake, drawing the attention in case the structure does not fulfill with the minimum safety conditions.

Fig. (7) shows a comparison of the vulnerability curves when the slab thickness is variable, while the plan configura- 


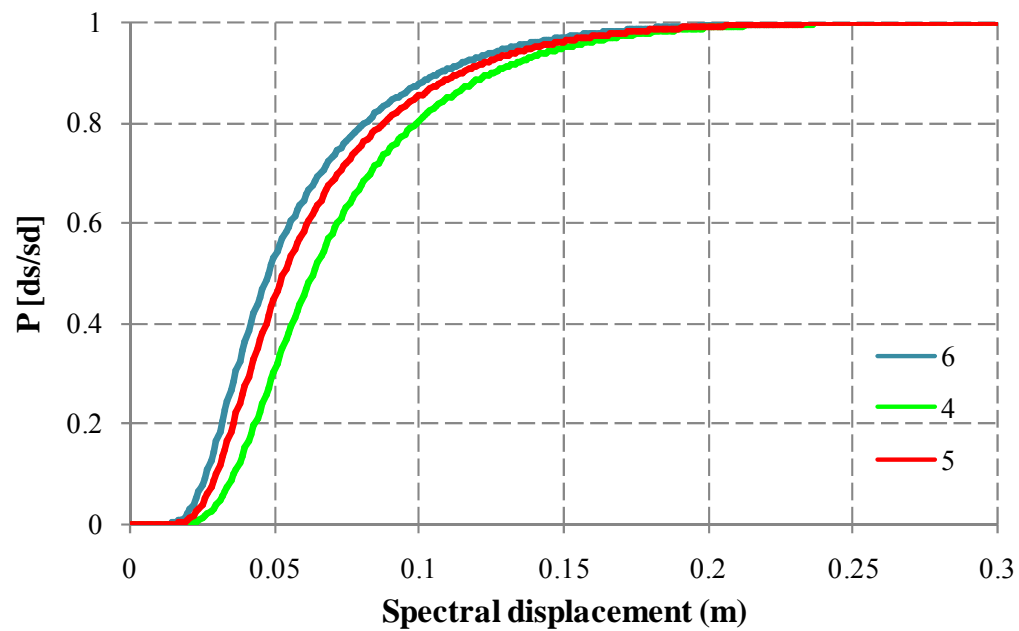

Fig. (7). Vulnerability curves for 8 story, square plan configuration structure with slab thicknesses of $0.1,0.12$ and $0.15 \mathrm{~m}$

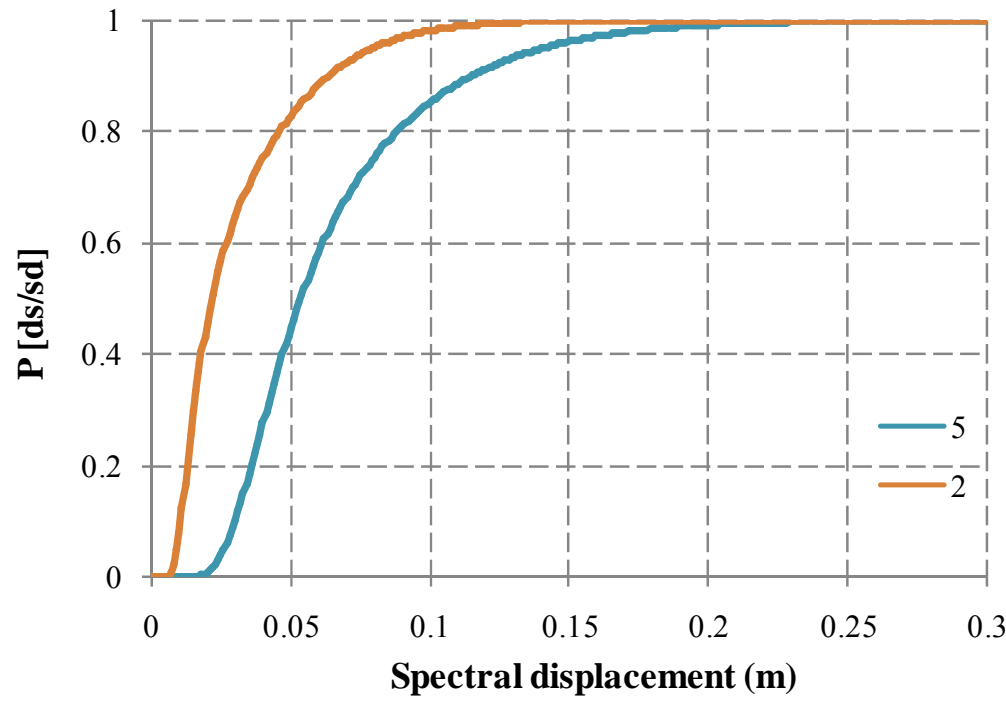

Fig. (8). Vulnerability curves for square plan configuration with $0.12 \mathrm{~m}$ slab thickness and 4 and 8 story, respectively.

tion and the number of story remains constant. The same trend is observed in all the cases, that is, the vulnerability is directly proportional with the slab thickness. Even though the maximum base shear force increases, the maximum top displacement decreases as it can be seen in Fig. (3). This last parameter has higher influence on the overall behavior of the structure which will be more vulnerable. For this reason, it is recommended to choose carefully the slab thickness dimensions in accordance with the design conditions.

If a spectral displacement of $0.05 \mathrm{~m}$ is considered, an increase of about $10 \%$ will appear for each slab thickness considered; - for a slab thickness of $0.1 \mathrm{~m}$, the damage index is about $30 \%$, for a slab thickness of $0.12 \mathrm{~m}$, the damage index is about $42 \%$ and for a slab thickness of $0.15 \mathrm{~m}$, the damage index is about $51 \%$.

It can be noticed that the vulnerability increases with the decrease of the number of story. Fig. (8) compares the vulnerability curves for a structure with a square plan configuration and with $0.12 \mathrm{~cm}$ slab thickness when the number of story varies from 4 (mid-rise structure) to 8 story (high-rise structure). If a spectral displacement of $0.05 \mathrm{~m}$ is considered an increase of about $400 \%$ will appear between the high-rise and mid-rise considered structures; for 8 story, the damaged index is about $42 \%$ and for 4 story it is about $82 \%$.

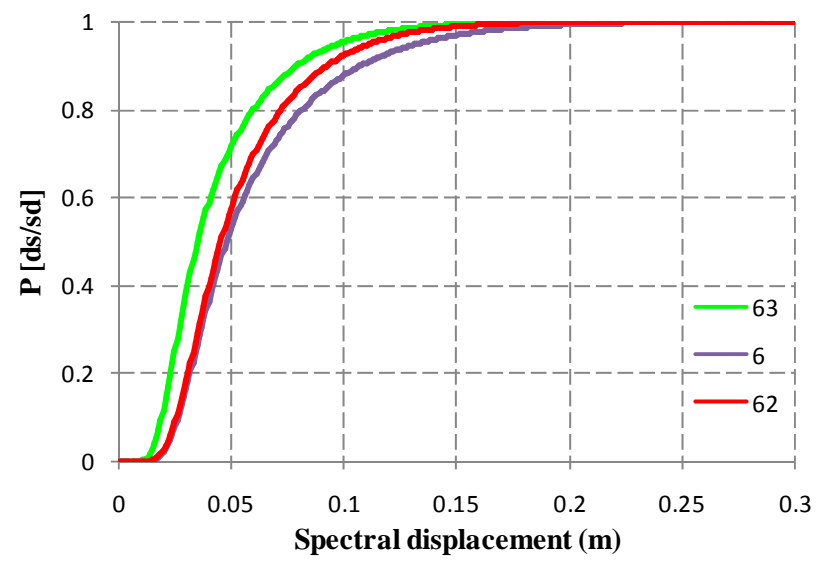

Fig. (9). Vulnerability curve for 8 story building with $0.15 \mathrm{~m}$ slab thickness considering different plan configurations: square, rectangular and L shape. 
Fig. (9) shows the vulnerability curves for the case when the plan configuration is varied. In this case, even if in Fig. (4), the highest capacity curve was obtained for the L shape plan configuration, in case of the vulnerability curves the tendancy is reversed. The most vulnerable one is the $\mathrm{L}$ shape building and the less vulnerable one is the building with square plan configuration. In all the analyzed situation, the differences are not excessively high, but confirm the idea presented previously that a complex plan configuration is not the best choice in seismic areas.

If a spectral displacement of $0.05 \mathrm{~m}$ is considered, an increase of about $8 \%$ is noticed between the building with square plan configuration and that with the rectangular one. The damage index increases from $60 \%$ in case of a rectangular plan configuration to $75 \%$ for an L shape plan configuration.

\section{CONCLUDING REMARKS}

The described methodology, based on nonlinear static analysis, has been developed and improved during the last 10 years and proved its efficiency in research projects like Hazus, Risk-UE, CAPRA and SARA. Vulnerability curves are crucial in order to reduce seismic impact on the built environment and on society.

The obtained results reveal that there is a directly proportional relation between the slab thickness and the vulnerability of the structure. The vulnerability increases with the slab thickness regardless the plan configuration or the number of considered story.

When the effect of the number of story was considered, it was concluded that the structures with a smaller number of levels are more vulnerable. This conclusion is valid only for the mid-rise and high-rise structures considered herein, because the low-rise structures were not considered in this study.

Referring to the influence of the plan configuration, the $\mathrm{L}$ shaped building resulted to be the most vulnerable, what is in accordance with other studies about the influence of irregular plan configuration on the overall seismic behavior of a structure.

\section{CONFLICT OF INTEREST}

The authors confirm that this article content has no conflict of interest.

\section{ACKNOWLEDGEMENTS}

This work has been partially sponsored by the Ministry of Education and Science of Spain, project "Enfoque integral y probabilista para la evaluacion del riesgo sismico en España, CoPASRE”, (CGL2011-29063).

\section{REFERENCES}

[1] J. J. Egozcue, A. H. Barbat, J. A. Canas, J. Miquel, and E. Banda, "A method to estimate occurrence probabilities in low seismic activity regions", Earthquake Engineering and Structural Dynamics, vol. 20, no. 1, pp. 43-60, 1991.

[2] M. L. Carreño, O. D. Cardona, and A. H. Barbat, "Método numérico para la evaluación holística del riesgo sísmico utilizando la teoría de conjuntos difusos", Revista internacional de métodos numéricos para cálculo y diseño en ingeniería, vol. 1, no. 30, pp. 25-34, 2014.
[3] N. Lantada, L. G. Pujades, and A. H. Barbat, "Vulnerability index and capacity spectrum based methods for urban seismic risk evaluation. a comparison", Natural Hazards, vol. 51, pp. 501-524, 2009.

[4] L. G. Pujades, A. H. Barbat, R. González-Drigo, J. Avila, and S. Lagomarsino, "Seismic performance of a block of buildings representative of the typical construction in the Eixample district in Barcelona (Spain)", Bulletin of Earthquake Engineering, vol. 1, no. 10, pp. 331-349, 2012.

[5] J. E. Hurtado, and A. H. Barbat, "Improved stochastic linearization method using mixed distributions", Structural Safety, vol. 1, no. 18, pp. 49-62, 1996.

[6] X. Martinez, S. Oller, F. Rastellini, and A. H. Barbat, "A numerical procedure simulating RC structures reinforced with FRP using the serial/parallel mixing theory", Computers \& Structures, vol. 86, pp. 1604-1618, 2008.

[7] EC8. "European Committee for Standardization, prEN-1998-1, Eurocode No. 8, Design of Structures for Earthquake Resistance, Part 1: General Rules, Seismic Actions and Rules for Buildings", Brussels, 2003.

[8] ASCE. "FEMA 356 Prestandard and Commentary for the Seismic Rehabilitation of Buildings", ASCE for the Federal Emergency Management Agency, Washington, DC, November 2000.

[9] ATC-40. "Seismic evaluation and retrofit of concrete buildings". Applied Technology Council, Redwood City, California, 1996.

[10] E. Cosenza, and G. Monti, "Assessment and Reduction of the Vulnerability of Existing Reinforced Concrete Buildings", The state of Earthquake Engineering Research in Italy: the ReLUIS-DPC 20052008 Project, 51-110, Napoli, Italy, 2009.

[11] M. N. Fardis, "Assessment of RC structures to lateral loads", In: Proceedings of International Seminar on evolutions in experimentations for structures, CIAS, Corinth, Greece, 1998

[12] A. Masi, "Seismic vulnerability assessment of gravity load designed R/C frames", Bulletin of Earthquake Engineering, vol. 1, pp. 371395, 2003.

[13] C. P. Olariu, I. Olteanu, Y. F. Vargas, and M. Budescu, "Influence of Soil Conditions on Building Vulnerability", Bulletin of the Polytechnic Institute of Jassy, Romania, Tomme, vol. LIV(LVIII), no. 3 , pp. 22-30, 2011.

[14] I. Toma, I. Olteanu, and M. Budescu, "Plan configuration Influence on Vulnerability of Reinforced Concrete Frame Structure in Seismic Areas", In: $4^{\text {th }}$ International Conference on Advanced Materials and Systems, Bucharest, Romania, pp. 571-575, ISSN 2068-0783, 27-29 September 2012.

[15] A. Prabhu, "Seismic Evaluation of 4-Story Reinforced Concrete Structure by Non-Linear Static Pushover Analysis", a thesis submitted in partial fulfillment of the requirements for the degree of bachelor of technology in civil engineering, Department of Civil Engineering National Institute of Technology Rourkela, 2013.

[16] Y. F. Vargas, L. G. Pujades, A. H. Barbat, and J. E. Hurtado, "Evaluación probabilista de la capacidad, fragilidad y daño sísmico en edificios de hormigón armado", Revista internacional de métodos numéricos para cálculo y diseño en ingeniería, vol. 29, no. 2, pp. 63-78, 2013.

[17] O. D. Cardona, M. G. Ordaz, M. C. Marulanda, and A. H. Barbat, "Estimation of probabilistic seismic losses and the public economic resilience-An approach for macroeconomic impact evaluation", Journal of Earthquake Engineering, vol. 12, no. S2, pp. 60-70, 2008.

[18] M. C. Marulanda, O. D. Cardona, and A. H. Barbat, "Revealing the socioeconomic impact of small disasters in Colombia using the DesInventar database", Disasters, vol. 34, no. 2, pp. 552-570, 2010.

[19] F. López Almansa, A. H. Barbat, and J. Rodellar, "SSP algorithm for linear and non-linear dynamic response simulation", International Journal for Numerical Methods in Engineering, vol. 26, no. 12, pp. 2687-2706, 1988.

[20] C. Molins, P. Roca, and A. H. Barbat, "Flexibility-based linear dynamic analysis of complex structures with curved-3D members", Earthquake Engineering and Structural Dynamics, vol. 27, no. 7, pp. 731-747, 1998.

[21] O. Salomon, S. Oller, and A. H. Barbat, "Finite element analysis of base isolated buildings subjected to earthquake loads", International Journal for Numerical Methods in Engineering, vol. 46, no. 10, pp. 1741-1761, 1999.

[22] M. C. Griffith, and A. V. Pinto, "Seismic retrofit of RC buildings - a review and case study", University of Adelaide, Adelaide, Australia 
and European Commission, Joint Research Centre, Ispra Italy, 2000.

[23] S. Otani, "Seismic Vulnerability Assessment of Reinforced Concrete Buildings", Faculty of Engineering, University of Tokyo, Series B, Vol., XLVII, October 2000, pp. 5-28.

[24] D. C. Rai, "Seismic Evaluation and Strengthening of Existing Buildings" IIT Kanpur and Gujarat State Disaster Mitigation Authority, 2005.

[25] R. K. Goel, "Evaluation of Current Nonlinear Static Procedures for Reinforced Concrete Buildings", In: $14^{\text {th }}$ World Conference on Earthquake Engineering, Beijing, China, October 12-17, 2008.

[26] B. Ozer, and M. A. Erberik, "Vulnerability of Turkish Low-Rise and Mid-Rise Reinforced Concrete Frame Structures", Journal of Earthquake Engineering, vol. 12, no. S2, pp. 2-11, 2008. ISSN: 1363-2469 print/1559-808X [online], doi: 0.1 .1080 / 13632460802012687.

[27] E. Cosenza, and G. Monti, "Assessment and Reduction of the Vulnerability of Existing Reinforced Concrete Buildings", The state of Earthquake Engineering Research in Italy: the ReLUIS-DPC 20052008 Project, Napoli, Italy, 2009, pp. 51-110.

[28] S. Sattar, and A. B. Liel, "Seismic Performance of Reinforced Concrete Frame Structures with and without Masonry Infill Walls", In: $9^{\text {th }}$ U.S. National and $10^{\text {th }}$ Canadian Conference on Earthquake Engineering, Toronto, Canada, July, 2010.

[29] N. Lantada, J. Irizarry, A. H. Barbat, X. Goula, A. Roca, T. Susagna, and L. G. Pujades, "Seismic Hazard and risk scenarios for Barcelona, Spain, using the Risk-UE vulnerability index method", Bulletin of Earthquake Engineering, vol. 8, pp. 201-229, 2010.

[30] J. Irrizari, N. Lantada, L. G. Pujades, A. H. Barbat, X. Goula, T. Susagna, and A. Roca, "Ground-shaking scenarios and urban risk evaluation of Barcelona using the risk-UE capacity spectrum based method", Bulletin of Earthquake Engineering, vol. 9, pp. 441-466, 2011

[31] B. Monavari, A. Massumi, and A. Kazem, "Estimation of Displacement Demand in RC Frames and Comparing with Target Displacement Provided by FEMA-356", In: $15^{\text {th }}$ World Conference on Earthquake Engineering, Lisbon, Portugal, 24-28 September, 2012.

[32] A. Bakhshi, and M. Ansari, "Development of seismic fragility curves for reinforced concrete tall buildings", In: Proceedings of the 9th International Conference on Structural Dynamics, EURODYN 2014, Porto, Portugal, 2014. ISSN: 2311-9020; ISBN: 978-972752-165-4

[33] Y. J. Park, and A. H. S. Ang, "Mechanistic seismic damage model for reinforced concrete", Journal of Structural Engineering, vol. 111 , no. 4, pp. 722-739, 1985.
[34] L. Esteva, "Seismic reliability analysis for vulnerability assessment and performance-based design of irregular buildings", In: $4^{\text {th }}$ International Symposium on Reliability, Engineering and Risk Management, Istanbul, Turkey, 20-24 May 2014.

[35] SAP 2000, "CSI Analysis Reference Manual for SAP2000, ETABS SAFE and CSiBridge", Berkeley, California, USA, March 2013.

[36] M. Mouzzoun, O. Moustachi, A. Taleb, and S. Jalal, "Seismic performance assessment of reinforced concrete buildings using pushover analysis", IOSR Journal of Mechanical and Civil Engineering, vol. 5, no. 1, pp. 44-49, 2013. ISSN: 2278-1684.

[37] A. H. Barbat, and L. M. Bozzo, "Seismic analysis of base isolated buildings", Archives of Computational Methods in Engineering, vol. 4, no. 2, pp. 153-192, 1997.

[38] S. Oller and A. H. Barbat, "Moment-curvature damage model for bridges subjected to seismic loads", Computer Methods in Applied Mechanics and Engineering, vol. 195, pp. 4490-4511, 2006.

[39] J. Faleiro, S. Oller, and A. H. Barbat, "Plastic-damage seismic model for reinforced concrete frames", Computers and Structures, vol. 86, no. 7-8, pp. 581-597, 2008.

[40] J. Faleiro, S. Oller, and A. H. Barbat, "Plastic-damage analysis of reinforced concrete frames", Engineering Computations, vol. 27, no. 1 , pp. 57-83, 2010.

[41] S. Lagomarsino, In: "Vulnerability assessment of historical buildings", C.S. Oliveira, A. Roca and X. Goula, Eds, Assessing and Managing Earthquake Risk, Colectión: Geotechnical Geological and Earthquake Engineering, vol. 2, 2006, pp. 135-158.

[42] A. H. Barbat, M. L. Carreño, O.D. Cardona, and M. C. Marulanda "Evaluación holística del riesgo sísmico en zonas urbanas", Revista internacional de métodos numéricos para cálculo y diseño en ingeniería, vol. 27, no. 1, pp. 3-27, 2011.

[43] I. Olteanu, Y. F. Vargas, A. H. Barbat, M. Budescu, and L. G. Pujades, "Vulnerability and risk evaluation for a reinforced concrete frame", Bulletin of the Polytechnic Institute of Jassy, Romania, Tomme, vol. LVIII, Fasc. 3, pp. 9-20, 2011. ISSN 1224-3884.

[44] I. Olteanu, A. Alistar, and M. Budescu, "Nonlinear analysis of reinforced concrete frames in atena 3D", Bulletin of the Polytechnic Institute of Jassy, Romania, Tomme, vol. LVII, no. 2, pp. 93-103, 2011. ISSN: 1224-3884.

[45] I. Olteanu, "Vulnerability assessment for reinforced concrete frame structures subjected to seismic loading", PhD thesis, Technical University "Gheorhe Asachi" of Iasi, Faculty of Civil Engineering and Building Services, 2011.

[46] P100-2013, "Cod de proiectare seismică - Partea I - Prevederi proiectare pentru clădiri”, Bucuresti 2013.

Received: October 14, 2014

Revised: November 12, 2014

Accepted: December 01,2014

(C) Olteanu et al.; Licensee Bentham Open.

This is an open access article licensed under the terms of the Creative Commons Attribution Non-Commercial License (http://creativecommons.org/licenses/ by-nc/3.0/) which permits unrestricted, non-commercial use, distribution and reproduction in any medium, provided the work is properly cited. 